\title{
Implementation of smoking signature as an improved biomarker predicting the response to immunotherapy
}

\author{
Haitang Yang ${ }^{1 \#}$, Wenyan $\mathrm{Ma}^{2 \#}$, Feng Yao ${ }^{1}$ \\ ${ }^{1}$ Department of Thoracic Surgery, Shanghai Chest Hospital, Shanghai Jiao Tong University, Shanghai, China; ${ }^{2}$ Clinical Research Center, Shanghai \\ Chest Hospital, Shanghai Jiao Tong University, Shanghai, China \\ \#These authors contributed equally to this work. \\ Correspondence to: Feng Yao. Department of Thoracic Surgery, Shanghai Chest Hospital, Shanghai Jiao Tong University, West Huaihai 241, Shanghai \\ 200030, China. Email: yaofeng@shsmu.edu.cn. \\ Response to: Li M, Zhao LY. Smoking signature as a biomarker for immunotherapy. Transl Lung Cancer Res 2022. doi: 10.21037/tlcr-21-966
}

Submitted Jan 10, 2022. Accepted for publication Jan 21, 2022.

doi: $10.21037 /$ tlcr-22-28

View this article at: https://dx.doi.org/10.21037/tlcr-22-28

We thank Li et al. for showing interest in our recent work demonstrating the use of heavy smoking history as a potential marker for predicting the clinical responses to immune checkpoint inhibitors (ICIs) in non-small cell lung cancer patients (1).

Li et al. specifically raised important and complementary points on the potential interpretations of smoking signature as a biomarker candidate predictive of ICIs response. Drawing on literature-based evidence, they proposed that the better response to ICIs associated with heavy exposure to tobacco is more likely to be due to the increased tumor mutational burden (TMB), as opposed to microsatellite instability (MSI). As they pointed out, lung cancer is rarely associated with high MSI, although the detailed smoking information in these studied cohorts has not been specified $(2,3)$. Available research also supports the association between TMB and smoking exposure (4-6). In this regard, we appreciated and agreed with $\mathrm{Li}$ and colleagues that TMB weights more than MSI in terms of interpreting the above observations. Nonetheless, a well-designed study is needed to investigate the link of tobacco exposure with TMB, and in particular, whether the heavy smoking history holds equal weights to high TMB for predicting response to ICIs in the clinic. Addressing this question would greatly improve the cost-effectiveness of ICIs, and facilitate the clinical practice.

In conclusion, despite the limitations mentioned by $\mathrm{Li}$ et al., our study revealed that lung cancer patients with heavy smoking history had improved responses to ICIs. Superior biomarkers for predicting the response to ICIs are urgently required to select patients for ICIs, smoking signature is a promising marker because of its high clinical utility and low cost.

\section{Acknowledgments}

Funding: None.

\section{Footnote}

Provenance and Peer Review: This article was commissioned by the editorial office, Translational Lung Cancer Research. The article did not undergo external peer review.

Conflicts of Interest: All authors have completed the ICMJE uniform disclosure form (available at https://tlcr.amegroups. com/article/view/10.21037/tlcr-22-28/coif). The authors have no conflicts of interest to declare.

Ethical Statement: The authors are accountable for all aspects of the work in ensuring that questions related to the accuracy or integrity of any part of the work are appropriately investigated and resolved.

Open Access Statement: This is an Open Access article

$\wedge$ ORCID: 0000-0002-8732-5910. 
distributed in accordance with the Creative Commons Attribution-NonCommercial-NoDerivs 4.0 International License (CC BY-NC-ND 4.0), which permits the noncommercial replication and distribution of the article with the strict proviso that no changes or edits are made and the original work is properly cited (including links to both the formal publication through the relevant DOI and the license). See: https://creativecommons.org/licenses/by-nc-nd/4.0/.

\section{References}

1. Yang H, Ma W, Sun B, et al. Smoking signature is superior to programmed death-ligand 1 expression in predicting pathological response to neoadjuvant immunotherapy in lung cancer patients. Transl Lung Cancer Res 2021;10:3807-22.

2. Luchini C, Bibeau F, Ligtenberg MJL, et al. ESMO recommendations on microsatellite instability testing for immunotherapy in cancer, and its relationship

Cite this article as: Yang $\mathrm{H}, \mathrm{Ma}$ W, Yao F. Implementation of smoking signature as an improved biomarker predicting the response to immunotherapy. Transl Lung Cancer Res 2022;11(1):124-125. doi: 10.21037/tlcr-22-28 with PD-1/PD-L1 expression and tumour mutational burden: a systematic review-based approach. Ann Oncol 2019;30:1232-43.

3. Goodman AM, Sokol ES, Frampton GM, et al. Microsatellite-Stable Tumors with High Mutational Burden Benefit from Immunotherapy. Cancer Immunol Res 2019;7:1570-3.

4. Wang X, Ricciuti B, Nguyen T, et al. Association between Smoking History and Tumor Mutation Burden in Advanced Non-Small Cell Lung Cancer. Cancer Res 2021;81:2566-73.

5. Nagahashi M, Sato S, Yuza K, et al. Common driver mutations and smoking history affect tumor mutation burden in lung adenocarcinoma. J Surg Res 2018;230:181-5.

6. Stabile LP, Kumar V, Gaither-Davis A, et al. Syngeneic tobacco carcinogen-induced mouse lung adenocarcinoma model exhibits PD-L1 expression and high tumor mutational burden. JCI Insight 2021;6:e145307. 